\title{
Dental procedures cause stress in children with cerebral palsy?
}

\author{
Maria de Fátima-Monteiro Tomasin ${ }^{1}$, Giselle-Rodrigues de Sant'Anna ${ }^{2}$, Adriano-Tomio Hoshi ${ }^{1}$, Danilo-Antônio \\ Duarte $^{2}$
}

\author{
${ }^{1}$ Department of Pediatric Dentistry, School of Dentistry, Western Paraná State University, Brazil \\ ${ }^{2}$ Department of Graduate Studies, São Leopoldo Mandic School of Dentistry, Brazil
}

Correspondence:

Faculdade de Odontologia da Universidade Estadual do Oeste do Paraná, Brazil

fatima.tomasin@outlook.com

Received: 08/03/2021

Accepted: $11 / 10 / 202$

Tomasin MFM, de Sant'Anna GR, Hoshi AT, Duarte DA. Dental procedures cause stress in children with cerebral palsy? J Clin Exp Dent. 2021;13(11):e1112-7.

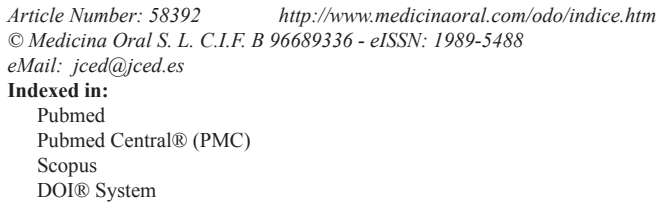

\begin{abstract}
Background: To evaluate the level of stress during dental care in children and preadolescents with cerebral palsy through biological and psychological parameters.

Material and Methods: A total of 38 children aged 7 to 12 years were divided into two groups: one with 18 children with cerebral palsy and the other with 20 healthy children (control group). Saliva was noninvasively collected before and after dental care to analyze salivary biomarkers. The Frankl Behavior Scale and the Facial Image Scale were applied.

Results: After the dental procedure, cortisol levels were significantly higher $(p=0.02)$ in the cerebral palsy group than in the control group. Salivary alpha-amylase was not significantly different between groups. Regarding psychological parameters, anxiety was significantly higher $(p=0.00012)$ in the cerebral palsy group than in the control group.

Conclusions: There was a change in physiological parameters (salivary cortisol and salivary alpha-amylase) and in psychological parameters (Frankl Behavioral Scale and Facial Image Scale) in patients with cerebral palsy, who exhibited higher stress and anxiety levels than did children without cerebral palsy.
\end{abstract}

Key words: Ortisol, physiological stress, dental care, cerebral palsy, dental treatment anxiety.

\section{Introduction}

The classic concept of disability seen as a medical model has been replaced by a social model concept. This means recognizing that disability is the product of individuals with disabilities and behavioral and environmental barriers that limit or prevent equal participation in interpersonal and social activities (1). Individuals with cerebral palsy (CP) are certainly included in this concept. CP is described as a neurodevelopmental disorder responsible for physical and cognitive impairment, with a prevalence of 2-2.5 cases per 1000 live births. It is considered the most common cause of physical disability in childhood (2). Children with CP require special medical and dental care because caries, periodontal diseases and malocclusions are relatively frequent (3-5), caused by difficulties in oral hygiene, dietary consistency, drugs, misinformation and limited access to dental services (6). Dental procedures usually are laborious due to the involuntary 
movements, constant spasms, marked stiffness and communication difficulties $(2,7)$. In this line of reasoning, it is inevitable that children with $\mathrm{CP}$ will require potentially anxiety- and stress-provoking dental interventions (3). However, there are few studies on this topic for this group of patients (8). The knowledge about the level of stress and anxiety can contribute to a better preparation of dental surgeon and his team in the proper care of these patients. Considering that salivary secretion may be affected by stressors, the present study chose the biomarkers cortisol and salivary alpha-amylase (sAA) $(9,10)$ and used the Frankl Behavior Scale (FBS) (11) and Facial Image Scale (FIS) (12), classical instruments used to analyze the emotional state of children, to assess the level of stress in children and preadolescents with CP.

\section{Material and Methods}

This was a cross-sectional study, conducted from $03 / 2019$ to $11 / 2019$, and the study subjects were children treated at the Pediatric Dentistry Clinic and Center of Dental Specialties. This study was approved by the research ethics committee of São Leopoldo Mandic School of Dentistry under number 2.431.543/2017, meeting the ethical and scientific requirements of Resolution 466/2012 of the National Health Council (Norms for Research involving Human Beings).

\section{-Sample Size Calculation and Selection}

G Power 3.1 software (University of Dusseldorf) was used to calculate the sample size required to detect an effect size of 0.8 , using the t-test for independent samples (cortisol), with an alpha error of 0.05 and $80 \%$ test power; the calculated sample size was 42 research subjects. A total of 42 individuals of both sexes and aged 7 to 12 years were randomly selected. The participants signed an informed assent form, and their guardians signed an informed consent form. Two groups were formed at a $1: 1$ ratio, defined as the cerebral palsy group (CPG) and the control group (CG). Individuals with $\mathrm{CP}$ were included in the CPG, and individuals without CP were included in the CG. Children with severe intellectual disabilities who used corticosteroids or drugs that altered oxygen saturation were excluded.

-Clinical Procedures and Saliva Collection

Saliva was collected in the evening to minimize the effects of the circadian cycle. A specific sampling device was used for collection (Salivette, Sarstedt), i.e., a centrifuge tube containing a cotton swab. With each individual in a dental chair, the cotton swab was placed on the floor of the mouth until completely moistened with saliva, and then the swab was returned to the tube. Saliva was collected from the participants in duplicate, before and after the dental prophylaxis. Both the saliva collection and the clinical procedure were performed by the researchers, who have expertise in pediatric dentistry and special needs patients.

For the analysis of cortisol, tubes containing saliva were sent under refrigeration $\left(2^{\circ}\right.$ to $\left.8^{\circ} \mathrm{C}\right)$ to UNILABOR in Cascavel, Paraná. The tubes were centrifuged at $1000 \mathrm{~g}$ to isolate the saliva, which was then subjected to electrochemiluminescence; the results are expressed in $\mathrm{nmol} / \mathrm{L}$. The tubes for the analysis of sAA were sent to the Biochemistry Laboratory in an ice box. The tubes were centrifuged at 4,500 rpm for 10 minutes, stored at $-20^{\circ} \mathrm{C}$ and subsequently analyzed. The analysis was performed using the method described by Fisher and Stein (13). Briefly, maltose was used as a standard, with the sample incubated in $1 \%$ starch solution in $20 \mathrm{mM}$ phosphate buffer, $\mathrm{pH} 7.0$, for 5 minutes at $37^{\circ} \mathrm{C}$. The reaction was stopped by adding dinitrosalicylic acid, and the mixture was kept in water at $98^{\circ} \mathrm{C}$ for 5 minutes. The sample was read in a spectrophotometer at $540 \mathrm{~nm}$, and the results are expressed in $\mathrm{U} / \mathrm{ml}$. For the evaluation of behavior during care, a trained pediatric dentist who was not a participant in the study applied the Frankl Behavior Scale (11) (FBS), an observational scale that classifies behavior into four categories (Fig. 1). The FIS (12) comprises

\begin{tabular}{|c|c|}
\hline TYPE OF BEHAVIOR & CHARACTERISTICS \\
\hline $\begin{array}{l}\text { Frankl I (- -) } \\
\text { (definitely negative behavior) }\end{array}$ & $\begin{array}{ll}- & \text { Refusal of treatment } \\
- & \text { Crying forcefully } \\
- & \text { Worst possible behavior }\end{array}$ \\
\hline $\begin{array}{l}\text { Frankl II (-) } \\
\text { (negative behavior) }\end{array}$ & $\begin{array}{ll}\text { - } & \text { Reluctant to accept treatment } \\
\text { - } & \text { Uncooperative } \\
\text { - } & \text { Some evidence of negative attitude but not } \\
\text { constant }\end{array}$ \\
\hline $\begin{array}{l}\text { Frankl III (+) } \\
\text { (positive behavior) }\end{array}$ & $\begin{array}{ll}\text { - } & \text { Acceptance of treatment with caution } \\
\text { - } & \text { Willingness to cooperate } \\
\text { - } & \text { Follows instructions } \\
\text { - } & \text { Somewhat reserved attitude }\end{array}$ \\
\hline $\begin{array}{l}\text { Frankl IV }(++) \\
\text { (definitely positive behavior) }\end{array}$ & $\begin{array}{ll}\text { - } & \text { Fully cooperative } \\
\text { - } & \text { Good rapport with the dentist } \\
\text { - } & \text { Interested in the dental procedure } \\
\text { - } & \text { Enjoying the situation }\end{array}$ \\
\hline
\end{tabular}

Fig. 1: Frank1 Behavior Scale. 
a series of five face figures, ranging from very unhappy (5) to very happy (1) (Fig. 2). The scale was presented to each individual by the researcher after the procedure so that he or she could choose the face that corresponded to their feelings during the dental procedure. For statistical analysis, the following tests were used: Student's t-test for paired samples, Yuen's t-test and non-parametric Mann-Whitney test for independent samples. The data were analyzed using the statistical software R for Windows, version 3.6.2 (2019-12-12). A 5\% significance level was considered for all analysis. lues in the CG and CPG. Regarding cortisol, the mean and standard deviation could not be used as measures of central tendency due to asymmetry on the right; therefore, the median and interquartile range (IQR) were used instead. The CPG showed greater data variability, evidenced by the IQR at both evaluation times. Based on the medians, the effect of the intervention on the groups was opposite, with a reduction in cortisol levels in the $\mathrm{CG}$ and an increase in the CPG. There was a significant difference only in the comparison between groups after the intervention $(p=0.02)$. Regarding sAA, the results

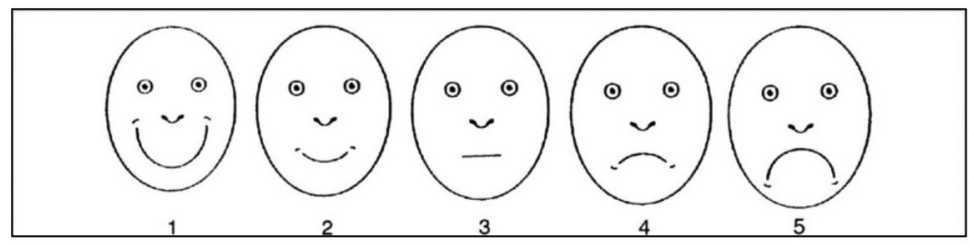

Fig. 2: Facial Image Scale.

\section{Results}

After the necessary exclusions, the sample included 38 children and preadolescents (22 females and 16 males), with 20 participants allocated to the CG and 18 to the CPG (Table 1). Table 2 shows the cortisol and sAA va-

Table 1: Sample characteristics according to group (CG and $\mathrm{CPG}$ ). The data are presented as absolute values with percentages in parentheses. For age, the data are presented as the mean and standard deviation (SD).

\begin{tabular}{|l|c|c|}
\hline Variable & \multicolumn{2}{|c|}{ Group } \\
\hline & CG & CPG \\
\hline $\mathrm{N}$ & $20(100 \%)$ & $18(100 \%)$ \\
\hline Female: N (\%) & $13(65 \%)$ & $9(50 \%)$ \\
\hline Male: N (\%) & $7(35 \%)$ & $9(50 \%)$ \\
\hline Age: mean (SD) & $8.9(1.2)$ & $9.7(1.6)$ \\
\hline
\end{tabular}

showed no significant difference between groups. Table 3 shows the results of the FBS and FIS evaluations. For the FBS, positive scale ratings were the most frequent results in both groups. For the FIS, the CG showed a predominance of level 1 (very happy), while for the CPG, there was a more dispersed distribution, with a predominance of level 4 (unhappy). There was a significant difference $(p=0.00012)$ in the scores for both scales between the groups.

\section{Discussion}

It is recognized that children with $\mathrm{CP}$ have a high rate of dental treatment needs $(3,4)$. Considering the exponential demand for dental care in this population (14), it is necessary to understand the level of stress experienced during clinical procedures. It is noteworthy that anxiety is a limiting factor in clinical interventions in children (15) and is amplified in those with CP, the target population of our study. To evaluate stress levels using physio-

Table 2: Cortisol and salivary alpha-amylase levels, as well as their respective p values, in the CG and CPG. The data are presented as the mean, with the standard deviation in parentheses, or as the median and interquartile range, when two numbers are presented in parentheses.

\begin{tabular}{|l|c|c|c|c|c|c|}
\hline Variable & \multicolumn{4}{|c|}{ Group } & \multicolumn{2}{c|}{ P-value } \\
\hline & $\begin{array}{c}\text { CG } \\
\text { Before }\end{array}$ & $\begin{array}{c}\text { CG } \\
\text { After }\end{array}$ & $\begin{array}{c}\text { CPG } \\
\text { Before }\end{array}$ & $\begin{array}{c}\text { CPG } \\
\text { After }\end{array}$ & $\begin{array}{c}\text { CPG before } \\
\text { X } \\
\text { CPG later }\end{array}$ & $\begin{array}{c}\text { CG after } \\
\text { X } \\
\text { CPG after }\end{array}$ \\
\hline $\begin{array}{l}\text { Cortisol } \\
\text { (nmol/L) }\end{array}$ & $\begin{array}{c}8.0 \\
(6.3-10.0)\end{array}$ & $\begin{array}{c}6.2 \\
(5.0-8.5)\end{array}$ & $\begin{array}{c}5.6 \\
(2.9-16)\end{array}$ & $\begin{array}{c}11.8 \\
(5.8-14.4)\end{array}$ & $0.12 \dagger$ & $\mathbf{0 . 0 2}+$ \\
\hline sAA $(\mathbf{U} / \mathbf{m L})$ & $13.9(8.1)$ & $18.1(9.3)$ & $18.0(8.4)$ & $17.0(10.1)$ & $0.65 \dagger$ & $0.69 \S$ \\
\hline
\end{tabular}

Legend: CG, control group; CPG, cerebral palsy group; sAA: salivary alpha-amylase.

$\dagger$ Student’s t-test for paired samples; $\$$ Yuen’s test; $\S$ Mann-Whitney test. 
Table 3: Distribution of data (percentage and count), with $\mathrm{p}$ values, obtained using behavioral scales (FBS and FIS) after the intervention.

\begin{tabular}{|l|c|c|c|}
\hline Variable & \multicolumn{2}{|c|}{ Group } & P value* \\
\hline Frankl Behavior Scale & CG & CPG & \\
\hline Definitely negative & $5.0 \%(1)$ & $0 \%(0)$ & 0.00012 \\
\hline Negative & $0 \%(0)$ & $38.9 \%(7)$ & \\
\hline Positive & $50.0 \%(10)$ & $55.5 \%(10)$ & \\
\hline Definitely positive & $45.0 \%(9)$ & $5.6 \%(1)$ & \\
\hline Facial Image Scale & & & \\
\hline 5 (very unhappy) & $0 \%(0)$ & $5.6 \%(1)$ & 0.00012 \\
\hline 4 & $0 \%(0)$ & $33.3 \%(6)$ & \\
\hline 3 & $15.0 \%(3)$ & $22.2 \%(4)$ & \\
\hline 2 & $15.0 \%(3)$ & $27.8 \%(5)$ & \\
\hline 1 (very happy) & $70.0 \%(14)$ & $11.1 \%(2)$ & \\
\hline
\end{tabular}

Legend: CG, control group; CPG, cerebral palsy group; FBS, Frankl Behavioral Scale; FIS, facial image scale. *Mann-Whitney test

logical parameters, we chose salivary cortisol and sAA because samples for their analysis can be collected using noninvasive and painless procedures $(16,17)$. Painful stimuli produce a physiological response through excitation of the hypothalamic-pituitary-adrenal axis, resulting in the release of cortisol. sAA is an important salivary enzyme and is used as a potential marker of stress responses via central nervous system activity $(9,18)$. Considering behavioral and subjective measures, we chose to use the FBS and FIS to assess anxiety. Both instruments are validated, have established application, are easy to apply and have high reliability $(12,19,20)$. The use of a physiological indicator combined with a psychological indicator contributed to the reliability of our results. Cortisol levels significantly increased in the CPG after dental care; in the CG, there was a moderate decrease in cortisol. Although sAA showed a slight decrease from pretreatment to posttreatment in the $\mathrm{CPG}$, the difference was not significant. The difference between cortisol and sAA can be explained by the fact that cortisol is more sensitive to physical stimuli and that sAA is more sensitive to psychological stressors $(21,22)$. Due to the scarcity of studies in the literature on the level of stress in children with $\mathrm{CP}$, the other studies used for comparison with our study are different. Blomqvist et al. (23) and dos Santos et al. (18) analyzed populations with attention deficit/hyperactivity disorder (ADHD) and global developmental delay (GDD), respectively, and found no significant differences in salivary cortisol levels between these groups and the controls. They also did not observe significant differences in cortisol levels before and after dental examinations. In contrast to these studies, others have observed higher salivary cortisol levels before dental prophylaxis, which may indicate that the anticipation of a dental visit generates greater anxiety than the visit itself $(10,22,24)$. However, in the present study, we observed a significant difference $(p=$ 0.02) in cortisol levels between groups after treatment. In the CPG, cortisol levels were higher after the intervention, similar to the findings of Yfanti et al. (25) and Gomes et al. (26), who analyzed healthy children. In the analysis of sAA, we observed in our study that there were no significant changes in sAA levels before and after dental treatment, both in the CPG and in the CG, similar to the findings of Yfanti et al. (25). There is a likely explanation for this result: the UNIOESTE Dental Clinic is a reference for care; therefore, the children and preadolescents in our study had previous experience with dental procedures.

In contrast, other studies have shown significantly higher sAA levels before dental procedures $(18,25)$. Furthermore, Rodrigues Gomes et al. (22) observed higher sAA levels after treatment. In addition to the disability, other factors can influence sAA responses, such as previous invasive dental procedures and age, as children in the age group below 72 months have higher sAA levels on clinical examination (15). Regarding the scales, our results showed that for the CG, the predominant FIS score was 1 (very happy), and for the CPG, the predominant score was 4 (unhappy); the difference in scores was significant $(p<0,01)$. Other studies also found that the predominant FIS score was 1 in healthy children $(27,28)$. Regarding the FBS, some studies have reported that most children showed positive or definitely positive behavior during dental care, corroborating our findings in the CG $(95 \%)(18,22,29)$. However, $38.9 \%$ of the CPG exhibited negative behavior, demonstrating a significant difference $(p<0,01)$ between the CG and CPG groups. Other studies found that predominant FIS scores were 2 and 3 in healthy children $(27,28)$. 
In a study by dos Santos (18) children with global developmental delay, no children showing true negative and $60,6 \%$ positive behavior based on the FBS. It is important to note that several factors, such as pain and age, can cause more negative behavior because younger patients, in addition to being more immature and susceptible to fear, are usually more agitated, requiring greater agility in care and knowledge of behavioral management techniques (30). In patients with $\mathrm{CP}$, behavior may also be influenced by factors such as the level of neurological involvement, involuntary movements and difficulty in opening the mouth (2).

Our postclinical intervention results indicate that the physiological and psychological parameters confirm the behavior of the study population, especially those in the CPG, who had higher cortisol levels, a higher occurrence of negative behaviors, based on the FBS, and a higher occurrence of anxiety, based on the FIS. These results indicate that patients with $\mathrm{CP}$ presented greater anxiety and stress regarding dental treatment. It is important to highlight some limitations of this study, such as greater sampling difficulty, verbal inability of the study population, and the occasional need for physical restraint. The comparison between the groups may be questionable, but the inclusion of healthy children was necessary due to the use of physiological markers as an objective parameter. In turn, these limitations were compensated by the methodological care in data collection, minimizing information bias. Despite the limitations and the small sample of this study, the results reinforce the analysis of the physiological parameters cortisol and sAA and of the Frankl Behavior and Facial Image scales indicated that dental procedures produced anxiety and stress in both groups, notably to a greater degree in the CPG. In addition, the results indicate that stress and anxiety produced during dental procedures should be managed by the dental surgeon. For this, it is necessary to invest in professional training policies starting in undergraduate curricula and extending to continuing education. These actions would certainly contribute to alleviating anxiety and stress and are essential for promoting the health of this population, which is sometimes underserved.

\section{References}

1. World Report on Disability 2011. Geneva: World Health Organization; 2011. Introduction. Available from: https://www.ncbi.nlm.nih. gov/books/NBK304065/

2. Novak I, Morgan C, Adde L, Blackman J, Boyd RN, Brunstrom-Hernandez J, et al. Early, Accurate Diagnosis and Early Intervention in Cerebral Palsy: Advances in Diagnosis and Treatment. JAMA Pediatr. 2017 Sep 1;171:897-907. Erratum in: JAMA Pediatr. 2017;171:919. 3. Chandra Pani S, AlEidan SF, AlMutairi RN, AlAbsi AA, Nasser AlMuhaidib D, Faisal AlSulaiman H, et al. The Impact of Gross Motor Function on the Oral Health-Related Quality of Life in Young Adults with Cerebral Palsy in Saudi Arabia. Int J Dent. 2020;2020:4590509. 4. Hotwani K, Sharma K. Dental management of early childhood caries in spastic quadriparesis: a case report and clinical guidelines. J Pediatr Rehabil Med. 2013;6:243-9.
5. Cardona-Soria S, Cahuana-Cárdenas A, Rivera-Baró A, Miranda-Rius J, Martín de Carpi J, Brunet-Llobet L. Oral health status in pediatric patients with cerebral palsy fed by oral versus enteral route. Spec Care Dentist. 2020;40:35-40.

6. Silva ELMSD, Góes PSA, Vasconcelos MMVB, Jamelli SR, Eickmann SH, Melo MMDC, et al. Atenção à saúde bucal de crianças e adolescentes com paralisia cerebral: percepções de pais e cuidadores. Cien Saude Colet. 2020;25:3773-3784.

7. Lima DSM, Barreto KA, Rank RCIC, Vilela JER, Corrêa MSNP, Colares V. Does previous dental care experience make the child less anxious? An evaluation of anxiety and fear of pain. Eur Arch Paediatr Dent. 2021;22:139-143.

8. Nater UM, Rohleder N. Salivary alpha-amylase as a non-invasive biomarker for the sympathetic nervous system: current state of research. Psychoneuroendocrinology. 2009;34:486-96.

9. Furlan NF, Gavião MB, Barbosa TS, Nicolau J, Castelo PM. Salivary cortisol, alpha-amylase and heart rate variation in response to dental treatment in children. J Clin Pediatr Dent. 2012;37:83-7.

10. Frankl SN, Shiere F, Fogels H. Should the parent remain with the child in the dental operatory? J Dent Child. 1962;29:150-163.

11. Buchanan H, Niven N. Validation of a Facial Image Scale to assess child dental anxiety. Int J Paediatr Dent. 2002;12:47-52.

12. Stein EA, Fischer EH. The resistance of alpha-amylases towards proteolytic attack. J Biol Chem. 1958;232:867-79.

13. Santos MT, Manzano FS. Assistive stabilization based on the neurodevelopmental treatment approach for dental care in individuals with cerebral palsy. Quintessence Int. 2007;38:681-7.

14. Malta CP, Guerreiro GG, Dornelles NM, Marques CT, Martins JS, Westphalen Bento L. Caregivers' Perceptions Regarding Oral Health Status of Children and Adolescents with Cerebral Palsy. J Clin Pediatr Dent. 2020;44:161-167.

15. Noorani H, Joshi HV, Shivaprakash P. Salivary Alpha Amylase as a Noninvasive Biomarker for Dental Fear and Its Correlation with Behavior of Children during Dental Treatment. Int J Clin Pediatr Dent. 2014;7:19-23.

16. Vineetha R, Pai KM, Vengal M, Gopalakrishna K, Narayanakurup D. Usefulness of salivary alpha amylase as a biomarker of chronic stress and stress related oral mucosal changes - a pilot study. J Clin Exp Dent. 2014;6:e132-7.

17. Chaturvedi Y, Chaturvedy S, Marwah N, Chaturvedi S, Agarwal S, Agarwal N. Salivary Cortisol and Alpha-amylase-Biomarkers of Stress in Children undergoing Extraction: An in vivo Study. Int J Clin Pediatr Dent. 2018;11:214-218.

18. dos Santos MJ, Bernabé DG, Nakamune AC, Perri SH, de Aguiar SM, de Oliveira SH. Salivary alpha amylase and cortisol levels in children with global developmental delay and their relation with the expectation of dental care and behavior during the intervention. Res Dev Disabil. 2012;33:499-505.

19. Radhakrishna S, Srinivasan I, Setty JV, D R MK, Melwani A, Hegde KM. Comparison of three behavior modification techniques for management of anxious children aged 4-8 years. J Dent Anesth Pain Med. 2019;19:29-36.

20. Abanto J, Vidigal EA, Carvalho TS, Sá SN, Bönecker M. Factors for determining dental anxiety in preschool children with severe dental caries. Braz Oral Res. 2017;31:e1

21. van Stegeren AH, Wolf OT, Kindt M. Salivary alpha amylase and cortisol responses to different stress tasks: impact of sex. Int J Psychophysiol. 2008;69:33-40.

22. Rodrigues Gomes SS, Barretobezerra AC, Maia Prado AC. Salivary biomarkers, vital signs and behaviour of pre-school children during their first dental visit. Eur J Paediatr Dent. 2013;14:279-83.

23. Blomqvist M, Holmberg K, Lindblad F, Fernell E, Ek U, Dahllöf G. Salivary cortisol levels and dental anxiety in children with attention deficit hyperactivity disorder. Eur J Oral Sci. 2007;115:1-6.

24. Yıldırım S, Bakkal M, Bulut H, Selek S. Quantitative evaluation of dental anxiety indicators in the serum and saliva samples of children treated under general anesthesia. Clin Oral Investig. 2018;22:23732380 .

25. Yfanti K, Kitraki E, Emmanouil D, Pandis N, Papagiannoulis L. 
Psychometric and biohormonal indices of dental anxiety in children. A prospective cohort study. Stress. 2014;17:296-304.

26. Gomes HS, Vieira LA, Costa PS, Batista AC, Costa LR. Professional dental prophylaxis increases salivary cortisol in children with dental behavioural management problems: a longitudinal study. BMC Oral Health. 2016;16:74

27. Khanduri N, Singhal N, Mitra M. The prevalence of dental anxiety and fear among 4-13-year-old Nepalese children. J Indian Soc Pedod Prev Dent. 2019;37:345-349.

28. Rajwar AS, Goswami M. Prevalence of dental fear and its causes using three measurement scales among children in New Delhi. J Indian Soc Pedod Prev Dent. 2017;35:128-133.

29. Kilinç G, Akay A, Eden E, Sevinç N, Ellidokuz H. Evaluation of children's dental anxiety levels at a kindergarten and at a dental clinic. Braz Oral Res. 2016;30:S1806-83242016000100701.

30. Alshoraim MA, El-Housseiny AA, Farsi NM, Felemban OM, Alamoudi NM, Alandejani AA. Effects of child characteristics and dental history on dental fear: cross-sectional study. BMC Oral Health. 2018;18:33.

\section{Ethics}

The study was conducted following the ethical principles of Helsinki declaration and was approved by the Research Ethics Committee of Faculdade São Leopoldo Mandic under number 2.431.543.

Informed consent was obtained from the patients' guardians.

\section{Source of Funding}

Without financing.

\section{Conflicts of interest}

All authors declare that they have no conflicts of interest or relevant financial relationships. 